\title{
POTENCIAL FUNCIONAL DO JAMELÃO E AÇAÍ: CAPACIDADE ANTIOXIDANTE E NUTRICIONAL
}

Tayanne Christine da Silva Bencardino ${ }^{1}$; Diogo Pires Manhanini ${ }^{1}$; Joel Pimentel de Abreu ${ }^{1}$; Ellen Mayra Menezes Ayres ${ }^{1}$; Luciana Ribeiro Trajano Manhães ${ }^{1}$ (tayanne @ bencardino.com.br) ${ }^{1}$ Universidade Federal do Estado do Rio de Janeiro (UNIRIO), Rio de Janeiro, RJ, Brasil

O açaí (Euterpe oleraceae) possui importante valor nutricional por apresentar elevados teores de lipídeos, fibras, vitaminas e minerais. Além disso, é rico em compostos fenólicos, dentre eles em antocianinas, que são substâncias antioxidantes. Ele é amplamente comercializado em todo território nacional na forma de polpas, sucos e sorvetes. O jamelão (Syzygium cumini) também possui altos teores de compostos fenólicos, como antocianinas e ácidos fenólicos, sendo, portanto, rico em substâncias antioxidantes e de grande potencial funcional. Vale ressaltar que o consumo de alimentos ricos em antioxidantes é um importante meio de tamponar danos celulares e doenças associadas. $\mathrm{O}$ objetivo do estudo foi avaliar a capacidade antioxidante da polpa de açaí e do fruto jamelão por soluções extratoras e metodologias analíticas diferentes, a fim de evidenciar seus potenciais antioxidantes. O açaí utilizado nas análises foi em forma de polpa congelada de um único lote (Palamaz $\left.{ }^{\circledR}\right)$. Foram coletados em torno $5 \mathrm{~kg}$ do fruto Jamelão, no ponto de maturação ótimo para consumo, de árvores localizadas na Universidade Federal Rural do Rio de Janeiro, em Seropédica $\mathrm{RJ}$, que foram congelados $\left(-10^{\circ} \mathrm{C}\right)$ até o momento das análises. $\mathrm{O}$ despolpamento dos frutos foi manual e a análise se deu com a polpa e casca do mesmo. Foram realizadas análises de antioxidantes pelo método de ABTS e DPPH com uso dos extratores metanol (1), metanol 50\% (2), acetona (3), sequencial (4) e água (5). Usou-se o software GraphPad Prism®, versão 5.00 e o nível de significância adotado foi de $5 \%$ (valor de $\mathrm{P}<0,05$ ) para análises estatísticas. Foi utilizado o teste ANOVA para comparação entre extratores e matrizes. A análise de DPPH revelou que açaí possui capacidade antioxidante superior ao do jamelão, em todos os extratores utilizados. Já o método de ABTS mostrou que não houve diferença significativa entre a capacidade antioxidante das frutas analisadas. Esses resultados foram diferentes do que foi estudado por Sá (2008), que salientam o jamelão com maior capacidade antioxidante que o açaí. Em relação aos extratores utilizados, o melhor extrator para açaí foi o sequencial (4) em ambas as análises. Em contrapartida, a água foi o melhor extrator do jamelão em ambos os métodos. Isso pode ter correlação com a natureza centesimal das matrizes, bem como suas características moleculares. Essa diferença pode ser explicada por diferenças metodológicas e pelo fato do açaí aqui analisado, ter sido em forma de polpa, visto que a obtenção do fruto no sudeste do Brasil é dificultada. Há de se considerar que frutos não possuem distribuição homogênea, variando conforme solo, clima, dentre outras intervenientes e isso também pode ser fator interferente nas diferenças encontradas entre esse estudo e a literatura.

Palavras-chave: Antioxidante; açaí; jamelão. 